\title{
Exogenous gibberellin and cytokinin in a novel system for in vitro germination and development of African iris (Dietes bicolor)
}

\author{
Lázara Aline Simões Silva ${ }^{1}$, Andrey de Oliveira Costa ${ }^{1}$, Diego Silva Batista ${ }^{2}$, Maurecilne Lemes da Silva ${ }^{3}$, \\ Antônio Paulino da Costa Netto ${ }^{4}$ Diego Ismael Rocha ${ }^{*}$ (ID
}

\author{
$10.1590 / 0034-737 X 202067050008$
}

\begin{abstract}
The availability of reliable and reproducible micropropagation systems is a decisive step to successfully propagate plant species with slow growth and low germination rate. The effect was investigated of gibberellin (GA) and cytokinin (CK) in the in vitro germination and development of Dietes bicolor (Steud.) Sweet ex Klatt. Seeds were inoculated in Water + Agar; in Murashige e Skoog (MS) medium without plant growth regulators (PGRs) and in MS medium supplemented with 1 or $2 \mathrm{mg} \mathrm{L}^{-1}$ gibberellic acid or 6-benzylaminopurine. The germination, growth, and architecture of the plants presented significant alterations according to the treatments. Germination percentage increased at $2 \mathrm{mg} \mathrm{L}^{-}$ ${ }^{1}$ GA. Plants grown on the GA-supplemented medium also showed larger leaves. The presence of CK in the culture medium induced the activation of axillary shoot buds and reduced the root length. CK and GA had antagonistic effects on the thickness of the leaf tissues. The activation of multiple shoots in plants cultured with CK in the medium allowed the in vitro propagation of approximately three plants per germinated seed. The results obtained in the present study bring an unprecedented description of a germination system for a higher yield in D. bicolor micropropagation.
\end{abstract}

Keywords: butterfly iris; iridaceae; in vitro germination; plant growth regulators; micropropagation; shoot proliferation.

\section{INTRODUCTION}

The flower market has a relevant impact on the world horticultural industry. Over the past 20 years, the production of ornamental products has grown consistently around the world, presenting great potential for expansion (Rabobank 2015, 2016). This distinction of the flower market is due to the constant incorporation of production and logistics technologies (Junqueira \& Peetz, 2017). Biotechnological tools such as in vitro propagation and genetic manipulation have been used as new approaches to optimize traditional production techniques favoring mass clonal propagation and the introduction of new cultivars in the ornamental plant market (Ascough et al., 2009; Azadi et al., 2016).
Iridaceae is a family of perennial monocots of recognized ornamental importance due to the large number of species cultivated and the beauty of its flowers and leaves. The family has about 2000 species mainly distributed in the Northern Hemisphere, Africa and Central and South America (Goldblatt et al., 2008). Some Iridaceae species have also been used as medicinal agents, since several compounds with biological activity, such as anti-inflammatory and antiallergic effects, have been identified in the leaf extracts (Rahman et al., 2003; Ayoub et al., 2018). Thus, micropropagation systems have been established for some species of the family as an alternative to accelerate the process of propagation, large-scale production and provide suitable material for breeding and

\footnotetext{
Submitted on November 19 $19^{\text {th }}, 2019$ and accepted on July $21^{\text {th }}, 2020$.

${ }^{1}$ Universidade Federal de Jataí, Programa de Pós-graduação em Agronomia, Jataí, Goiás, Brazil. lazara.aline@gmail.com; andreyolicosta@gmail.com

${ }^{2}$ Universidade Federal da Paraíba, Campus III, Departamento de Agricultura, Bananeiras, Paraíba, Brazil. diegoesperanca@gmail.com

${ }^{3}$ Universidade Estadual de Mato Grosso, Faculdade de Ciências Agrárias, Biológicas e Saúde, Tangará da Serra, Mato Grosso, Brazil. maurecilne@gmail.com

${ }^{4}$ Universidade Federal de Jataí, Instituto de Ciências Biológicas, Jataí, Goiás, Brazil. apcnetto@ gmail.com; dirocha@ufg.br

*Corresponding author: dirocha@ufg.br; diegoirocha@gmail.com
}

Rev. Ceres, Viçosa, v. 67, n.5, p. 402-409, sep/oct, 2020 
bioprospecting programs (Jevremovic et al., 2013). According to Ascough et al. (2009) nearly 40 species and hybrids of Iridaceae have been successfully micropropagated for commercial purposes and most were of the genera Crocus, Gladiolus and Iris. However, the in vitro performance of many Iridaceae species with ornamental potential remains unexplored.

The development of micropropagation systems for ornamental plant species whose in vitro studies are not well established is limited to understanding how plant growth regulators (PGRs) in the culture medium can affect the growth and development of these plants. Cytokinins (CKs) and gibberellins (GAs) stand out as PGRs acting in in vitro propagation processes. CKs act by stimulating the activation and growth of axilary shoot buds and differentiation during leaf development (Bar \& Ori, 2014; Barbier et al., 2019). GAs have been commercially applied in cereals, fruit trees and ornamental plants and are important in the processes of germination and plant elongation (Finch-Savage \& Leubner-Metzger, 2006; Chen et al., 2008; Urbanova \& Leubner-Metzger, 2016).

Dietes bicolor (Steud.) Sweet ex Klatt, popularly known as African iris or butterfly iris, is a perennial plant native to South Africa and widely distributed in tropical and subtropical regions (Pooley, 1998). It is an ornamental species of increasing commercial value, used in urban landscaping and in public gardens, squares and shopping facilities (Lubbe et al., 2011). This species presents slow vegetative development and low germination rate and propagation is clump division (Pooley, 1998). Thus, micropropagation could be a useful tool to overcome these problems. In addition, to the best of our knowledge, there are no reports describing the establishment of micropropagation systems for $D$. bicolor. Thus the objective of the present study was to investigate the effect of $\mathrm{GA}$ and $\mathrm{CK}$ on the in vitro germination and development of $D$. bicolor seedlings. This knowledge will be fundamental for the development of micropropagation protocols and biotechnological tools for this important ornamental monocot.

\section{MATERIAL AND METHODS}

\section{Plant material and culture conditions}

Seeds of D. bicolor collected in Rio Verde (1748’08.7"S, 5054’27.0"W) and Jataí (1752’51"S, $\left.51^{\circ} 42^{\prime} 0^{\prime \prime} \mathrm{W}\right)$, in the state of Goiás, Brazil, were aseptically disinfected by immersion in $70 \%(\mathrm{v} / \mathrm{v})$ ethanol for $2 \mathrm{~min}$ followed by immersion for $20 \mathrm{~min}$ in a non-diluted commercial sodium hypochlorite solution $(2.5 \%$ active chlorine; Super Globo Química ${ }^{\circledR}$, Contagem, MG, Brazil) with two drops of Tween-20 dispersant $0.1 \%$ (v/v) per 100 $\mathrm{mL}$ of solution. The disinfected seeds were then rinsed four times with autoclaved deionized water.
The seeds were inoculated in test tubes $(25 \times 150 \mathrm{~mm}$, Vidrolabor, Paulínia, SP, Brazil) containing 15 mL induction medium consisting of Murashige \& Skoog (1962) basal salt solution (MS), sucrose (3\% w/v), inositol $(0.01 \% \mathrm{w} /$ v) (Sigma Aldrich $\left.{ }^{\circledR}\right), 0.8 \%$ (w/v) agar $\left(\right.$ Merck $^{\circledR}$, Darmstadt, $^{2}$ Germany) and different concentrations $\left(1\right.$ and $\left.2 \mathrm{mg} \mathrm{L}^{-1}\right)$ of CK (6-Benzylaminopurine) or GA (Gibberellic acid). In the control treatment, the PGRs were not added (MS0). An additional control treatment was performed with seeds inoculated in a medium composed only of water and agar $(0.8 \%)$. The $\mathrm{pH}$ of all media was adjusted to $5.7 \pm 0.1$, and autoclaved at $120^{\circ} \mathrm{C}$ and $108 \mathrm{kPa}$ for $20 \mathrm{~min}$. PGRs were added after autoclaving by filter sterilization through Millipore filter $(0.22 \mu \mathrm{m})$.

After inoculation, the test tubes were kept for 90 days in a growth room at $26 \pm 2{ }^{\circ} \mathrm{C}$, with a $16 \mathrm{~h}$ photoperiod and $40 \mu \mathrm{mol} \mathrm{m}{ }^{-2} \mathrm{~s}^{-1}$ irradiance provided by two fluorescent lamps (Luz do Dia Especial, 20 W, Osram, Brazil). A subculture was performed for the same medium of each treatment after 45 days of culture. Thirty tubes were prepared for each treatment, with one seed per test tube.

\section{Germination and growth}

After 40 days of culture, the germination percentage was determined by counting seeds with root protrusion longer than $5 \mathrm{~mm}$. At 90 days of culture, the following growth parameters were evaluated: leaf length, root length, number of leaves per plant and number of buds per explant. The evaluations were carried out non-destructively.

\section{Rooting, shoot elongation and acclimatization}

After 90 days of culture, the seedlings were transferred to test tubes containing MS medium without PGRs (MS0), except for the plants obtained in the treatments supplemented with $\mathrm{CK}$, which were transferred to tubes containing MS medium supplemented with $2 \mathrm{mg} \mathrm{L}^{-1} \mathrm{GA}$ for elongation. The seedlings were then kept under these conditions for a further 30 days. Subsequently, they were transferred to MS medium without PGRs, for a further 30 days. In this phase, all the shoots obtained in treatments supplemented with CK were individualized for rooting.

After this, the plants were washed to remove the excess of culture medium, transferred to $300 \mathrm{~mL}$ plastic cups containing the commercial substrate Bioplant ${ }^{\circledR}$ and wrapped in plastic bags. After seven days, the plastic bags were removed and the plants were taken to the greenhouse. Plants surviving under greenhouse conditions for more than seven days were considered acclimatized.

\section{Microscopic and micromorphometric analyses}

For structural characterization, samples from the median region of the largest leaf of five plants of each 
treatment were collected after 90 days of in vitro culture. The samples were fixed in $4 \%$ paraformaldehyde, dehydrated through a graded ethanol series and embedded in acrylic resin (HistoResin, Leica ${ }^{\circledR}$, Wehrheim, Germany). Cross sections, $5-\mu \mathrm{m}$ thick, were obtained using a rotative microtome (RM2155, Leica Microsystems Inc., Deerfield, USA) and stained with toluidine blue (pH 4.8; O'Brien \& McCully, 1981). Images were captured under a light microscope (AX70TRF, Olympus Optical, Tokyo, Japan) equipped with a digital camera.

For the micromorphometric analysis, fifteen images were obtained per treatment, in which the mesophyll thickness, epidermis thickness (adaxial and abaxial) and total thickness of the leaf blade were measured. Ten measurements of each parameter per image were taken using the software Axioskop 1.0 (Zeiss, Germany), totaling 1800 measurements.

\section{Statistical analysis}

The experiment was carried out twice in a completely randomized design. Data were submitted to analysis of variance (ANOVA) using the SAS/STAT software (SAS, 2003) and the means were compared using the Tukey test at a level of 5\% significance.

\section{RESULTS}

\section{$G A$ increased the in vitro germination rate of D. bicolor seeds}

The in vitro culture conditions to which the $D$. bicolor seeds were submitted induced the germination and development of morphologically normal plants. Germination responses occurred between 25 and 30 days after inoculation. The supplementation of PGRs did not alter the the speed of germination (data not shown). However, GA at $2 \mathrm{mg} \mathrm{L}^{-1}$ significantly induced the highest germination percentage (78\%) after 40 days of culture (Figure 1a). In the other treatments, the percentage varied from $50 \%$ (water + agar) to $62 \%$ (MS0) (Figure 1a).

\section{$G A$ and CK altered the growth and phenotype of in vitro $D$. bicolor plants}

The seedlings of D. bicolor did not show any hyperhydric symptoms during in vitro cultivation, but their growth and phenotype presented significant alterations as affected by the PGRs (Figure 1b). Plants grown on medium supplemented with $2 \mathrm{mg} \mathrm{L}^{-1} \mathrm{GA}$ showed a significant increase in leaf length (Figure 1c), compared to the counterparts on MS0 (Figure 1c). The shortest leaf length was observed in the medium supplemented with $2 \mathrm{mg} \mathrm{L}^{-1} \mathrm{CK}$, where the plants had a significant reduction (75\%) compared to those grown on MS0 (Figure 1c). However, no significant difference was observed among the treatments for the number of leaves (Figure 1d). The number of shoots was bigger in the treatments supplemented with $\mathrm{CK}$, but there was no statistical difference between the CK concentrations (Figure 1e).

Supplementation of CK to the culture medium also inhibited the root development of in vitro D. bicolor seedlings (Figure 1f). In the treatments supplemented with 1 and $2 \mathrm{mg} \mathrm{L}^{-1} \mathrm{CK}$, root length reduction was $70.8 \%$ and $74.1 \%$, respectively, in comparison to the seedlings grown without PGRs (MS0), while the other treatments did not differ from the control (MS0) (Figure 1f).

\section{GA and CK antagonistically affected leaf anatomy of $\mathrm{D}$. bicolor}

The D. bicolor seedlings cultured under different concentrations of GA and CK presented leaves with the same anatomical characteristics: a uniseriate and amphistomatic epidermis and homogeneous mesophyll composed of 4 to 5 layers of parenchyma cells with idioblasts dispersed throughout the mesophyll (Figure 2a). However, PGRs promoted significant effects on quantitative anatomical parameters (Figure 2b-d). Seedlings grown with GA showed thinner epidermis, whereas those supplemented with CK did not differ from MS0 (Figure 2b).

The mesophyll thickness was reduced in leaves of seedlings grown in the presence of GA and in the medium without nurients (Figure 2b) but increased in plants grown with CK, both in comparison to MS0 (Figure 2b). The leaf blades of the seedlings grown with CK were significantly thicker (Figure 2a-c). On the other hand, seedlings cultured in the presence of GA and in the absence of nutrients in the culture medium presented thinner leaves (Figure 2a-c).

\section{CK induced multiple shoot formation in D. bicolor in vitro plants}

The CK supplementation in the culture medium promoted the activation of axilary shoot buds of $D$. bicolor (Figures 1e, 3a). The seedlings obtained were transferred to medium containing $2 \mathrm{mg} \mathrm{L}^{-1} \mathrm{GA}$, for elongation and rooting, reaching an average of $5-7 \mathrm{~cm}$ height and $74 \%$ rooting rate after 60 days culture (Figure $3 \mathrm{~b})$. Elongated and rooted plants of the different induction treatments were acclimatized (Figure $3 \mathrm{c}$ ). Seeds germinated in media supplemented with 1 and $2 \mathrm{mg} \mathrm{L}^{-1}$ CK regenerated, respectively, 2.5 and 2.8 plants on average (Figure 3d). However, the survival rate of the acclimatized plants obtained from media supplemented with CK was $87 \%$, while the other treatments presented $100 \%$ survival. 


\section{DISCUSSION}

PGRs signaling can control the plant development processes by reprogramming gene expression and rebalancing cell proliferation and differentiation (Fehér et al., 2003; Hepworth \& Lenhard, 2014; Xu \& Huang, 2014). Here, we report the effects of exogenous supplementation of GA and $\mathrm{CK}$ on the in vitro germination, development and propagation of $D$. bicolor plants.

The regulation of the germination process involves the hormonal balance between abscisic acid (ABA) and GA. While ABA promotes the establishment and maintenance of seed dormancy, GA acts in an
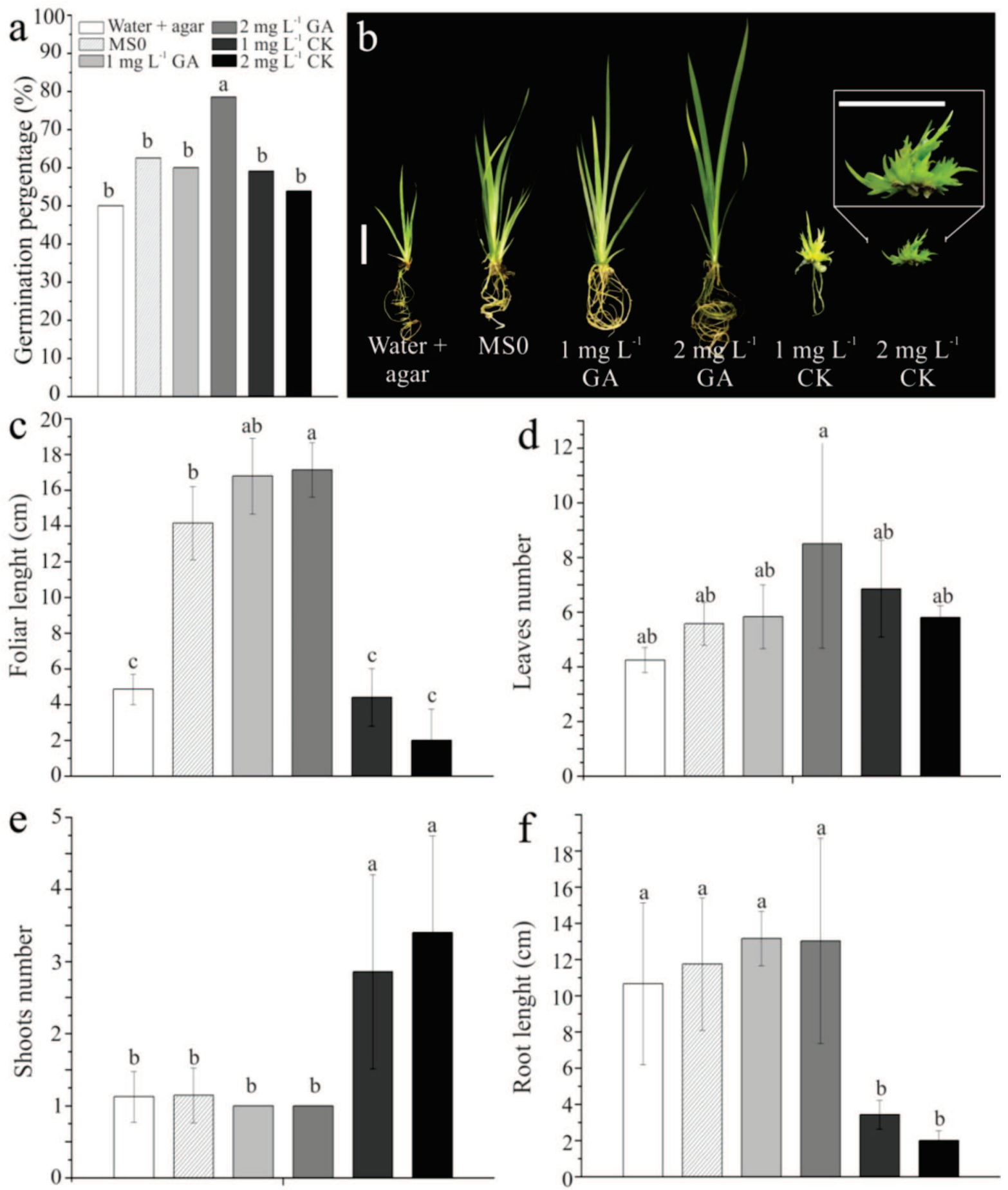

Figure 1: In vitro germination and morphometric analysis of Dietes bicolor in vitro seedlings. a. Germination percentage. $\mathbf{b}$. Phenotype of in vitro seedlings. c. Length of the longest leaf. d. Average number of leaves. e. Number of active shoots. f. Average length of the longest root. Error bars denote the standard deviation. Means followed by the same letters in each of the graphs do not differ from each other by the Tukey test at the $5 \%$ probability level. $\mathrm{Bar}=2 \mathrm{~cm}$. Abbreviations: $C K$, cytokinin; GA gibberellin, $M S O$ MS culture medium without plant growth regulators. 
antagonistic way, stimulating germination (Phengphachanh et al., 2012; Ruduœ et al., 2019). In fact, in the present study the highest germination rate was observed in the medium supplemented with the highest GA concentration. The increase in the endogenous GA/ $\mathrm{ABA}$ ratio in the seed from exogenous GA supplementation may have promoted the activity of hydrolytic enzymes, mobilizing stored reserves in the seeds and, consequently, leading to germination (Chen et al., 2008; Daviere \& Achard, 2013; Urbanova \& Leubner-Metzger, 2016).

In addition to germination, GAs regulate other diverse processes of plant development (Yamaguchi, 2008; Livne et al., 2015). Exogenous GA supplementation may have increased the cellular GA concentration (Gupta \& Chakrabarty, 2013), which plays an important role in cell division and elogation (Swain \& Singh, 2005), resulting in longer D. bicolor leaves. Similar results were observed
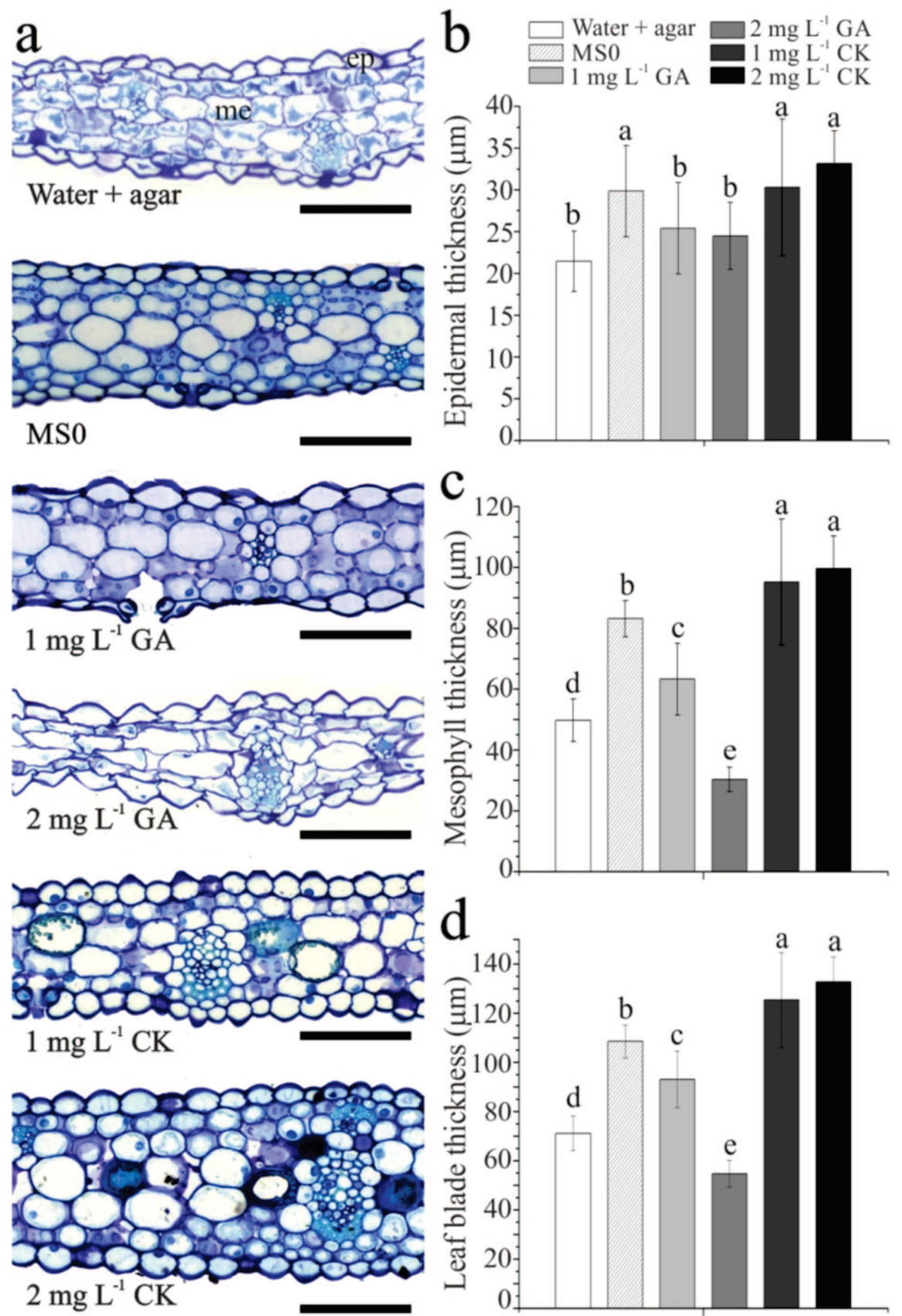

Figure 2: Micromorphometric characterization of Dietes bicolor in vitro seedlings. a. Cross sections of the leaves. b. Epidermal thickness $(\mu \mathrm{m})$. c. Mesophyll thickness $(\mu \mathrm{m})$. d. Leaf blade thickness $(\mu \mathrm{m})$. Error bars denote the standard deviation. Means followed by the same letters in each of the graphs do not differ from each other by the Tukey test at $5 \%$ probability level. Abbreviations: $C K$, cytokinin; $e p$ epidermis; GA gibberellin; me mesophyll. MSO MS culture medium without plant growth regulators. Bars $=50 \mu \mathrm{m}$. 

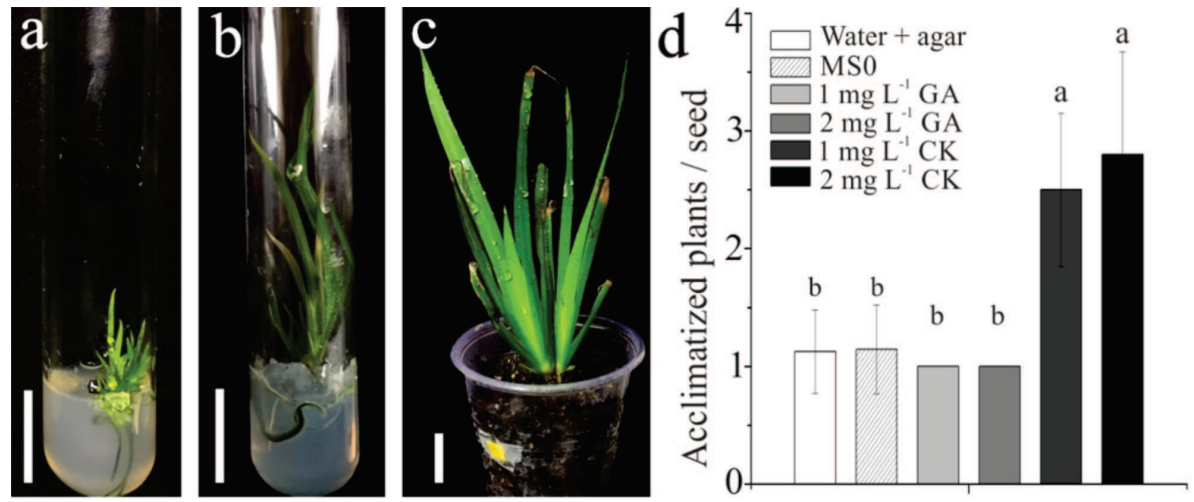

Figure 3: Shoot elongation and acclimatization of Dietes bicolor plants. a. Seedlings established in medium supplemented with $2 \mathrm{mg}$ $\mathrm{L}^{-1}$ CK. b. In vitro elongated plants after transfer to medium supplemented with $2 \mathrm{mg} \mathrm{L}^{-1} \mathrm{GA}$. c. Acclimatized plant. d. Number of acclimatized plants per germinated seed in the presence of different GA and CK concentrations. Error bars denote the standard deviation. Means followed by the same letters do not differ from each other by the Tukey test at $5 \%$ probability level. Abbreviations: $C K$, cytokinin; $G A$ gibberellin, $M S O$ MS culture medium without plant growth regulators. Bars $=2 \mathrm{~cm}$.

by Mushtaq et al. (2018) in onion (Allium cepa L.). On the other hand, in the present study no significant differences were observed in the root length of plants obtained in the presence of GA and without PGRs (MS0). This suggests that GA may play a limited role in $D$. bicolor root formation. In the literature, the effects of GA signaling on root system development are controversial. In Arabidopsis thaliana (L.) Heynh., GAs positively control the growth of the root apical meristem and the formation of lateral roots (UbedaTomás et al., 2009; Rizza et al., 2017). However, in Medicago truncatula Gaertn., another model species, GAs negatively regulate root growth resulting in shorter and thinner roots (Fonouni-Farde et al., 2019). These contrasting results suggest that GA effects on root system architecture are species-dependent.

The phenotype of $D$. bicolor plants was drastically altered by exogenous CK supplementation. CK signaling is vital for the development of vegetative organs in plants. In leaves, CKs act as juvenility factors, promoting morphogenesis and delaying differentiation and senescence. In the present study, CK supplementation promoted reduction in leaf size. This was also observed in A. thaliana, in which exogenous application of CK resulted in rosettes with small leaves (GreenboimWainberg et al., 2005). However, the presence of CK in the culture medium was also essential for the induction of multiple shoot proliferation in D. bicolor in vitro plants. Molecular CK signaling is required for the activation of axillary shoot buds by regulating the expression of genes such as STM and IPT7, which are required for the shoot apical meristem activity (Tucker \& Laux, 2007; Müller \& Leyser, 2011; Su et al., 2011). These responses demonstrate the compensatory effect of CK on shoot development, since high CK concentrations induce greater formation/activation of axillary buds, but can reduce the size of organs.
Unlike GAs, CK supplementation caused a reduction in the root length of in vitro D. bicolor plants. During root development, CKs act antagonistically to auxins, controlling the rates of differentiation and cell division in elongation, transition and division zones, through the direct inhibition of the gene $A H K 3$ and indirectly of the PIN family proteins (Perilli et al., 2010; Wybouw \& De Rybel, 2019). These processes help us to understand the response found here to $\mathrm{CK}$ treatments, where there was reduction in root length of $D$. bicolor plants.

GA and CK exhibited antagonistic effects on $D$. bicolor leaf anatomy. GA supplementation resulted in a reduction in leaf thickness, while CK increased the leaf tissue thickness. These results show that the relation between the two hormones is essential for determining leaf size. The antagonistic effects between GA and CK have been observed in several plant species (RodriguezFalcon et al., 2006; Tirichine et al., 2007; Maekawa et al., 2009) and studies have shown that these classes of hormones interact in a negative feedback regulation in several plant development processes (Fleishon et al., 2011). This mechanism may have evolved in order to adjust the balance between cell division, for which a high CK/ GA ratio is necessary (Jasinski et al., 2005; Bolduc \& Hake, 2009), and differentiation, where higher levels of GA and lower CK are required (Greenboim-Wainberg et al., 2005; Fleishon et al., 2011).

The induction of multiple shoots and the obtaining of three $D$. bicolor plants per seed in medium supplemented with CK with subsequent transfer to medium with GA demonstrates the potential of the in vitro germination system established here to propagate $D$. bicolor plants. Micropropagation protocols have been constantly optimized for Iridaceae species due to their ornamental and medicinal importance, but this is the first report on the in vitro performance of $D$. bicolor. 


\section{CONCLUSIONS}

We report here the effects on germination, growth, and development of D. bicolor plants when GA and CK levels are altered by their exogenous supplementation in the culture medium.

GA increased the in vitro germination rate of D. bicolor seeds and plants grown on GA-supplemented medium showed larger leaves.

CK induced axillary shoot buds and reduced root length. Seeds germinated on CK-supplemented medium gave rise to three regenerated plants per germinated seed.

Additionally, GA and CK exhibited antagonistic effects on D. bicolor leaf anatomy. GA supplementation resulted in a reduction in leaf thickness, while $\mathrm{CK}$ increased the leaf tissue thickness.

The results will contribute to the understanding of the in vitro performance of $D$. bicolor, and to the establishment of micropropagation systems of this important ornamental species.

\section{ACKNOWLEDGEMENTS, FINANCIAL SUPPORT AND FULL DISCLOSURE}

The authors would like to thank Mirian Machado Mendes and Valdnéa Casagrande Dalvi for kindly supplying seeds. This study was financed in part by the Coordenação de Aperfeiçoamento de Pessoal de Nível Superior - Brazil (CAPES) - Finance Code 001 and the Fundação de Amparo à Pesquisa do Estado de Goiás (FAPEG).

The authors declare that they have no conflicts of interest.

\section{REFERENCES}

Ascough GD, Erwin JE \& van Staden J (2009) Micropropagation of Iridaceae - a review. Plant Cell, Tissue and Organ Culture, 97:01-19.

Ayoub IM, Korinek M, Hwang TL, Chen BH, Chang FR, ElShazly M \& Singab ANB (2018) Probing the antiallergic and anti-inflammatory activity of biflavonoids and dihydroflavonols from Dietes bicolor. Journal of Natural Products, 81:243-253.

Azadi P, Bagheri H, Nalousi AM, Nazari F \& Chandler SF (2016) Current status and biotechnological advances in genetic engineering of ornamental plants. Biotechnology Advances, 34:1073-1090.

Bar M \& Ori N (2014) Leaf development and morphogenesis. Development, 141:4219-4230.

Barbier FF, Dun EA, Kerr SC, Chabikwa TG \& Beveridge CA (2019) An update on the signals controlling shoot branching. Trends in Plant Science, 24:220-236.

Bolduc N \& Hake S (2009) The maize transcription factor KNOTTED1 directly regulates the gibberellin catabolism gene ga2ox1. Plant Cell, 21:1647-1658.

Chen SY, Kuo SR \& Chien CT (2008) Roles of gibberellins and abscisic acid in dormancy and germination of red bayberry (Myrica rubra) seeds. Tree Physiology, 28:1431-1439.
Daviere JM \& Achard P (2013) Gibberellin signaling in plants. Development, 140:1147-1151.

Fehér A, Pasternak TP \& Dudits D (2003) Transition of somatic plant cells to an embryogenic state. Plant Cell, Tissue and Organ Culture, 74:201-228.

Finch-Savage WE \& Leubner-Metzger G (2006) Seed dormancy and the control of germination. New Phytologist, 171:501-523.

Fleishon S, Shani E, Ori N \& Weiss D (2011) Negative reciprocal interactions between gibberellin and cytokinin in tomato. New Phytologist, 190:609-617.

Fonouni-Farde C, Miassod A, Laffont C, Morin H, Bendahmane A, Diet A \& Frugier F (2019) Gibberellins negatively regulate the development of Medicago truncatula root system. Scientific Reports, 9:2335.

Goldblatt P, Rodriguez A, Powell MP, Davies JT, Manning JC, Van der Bank M \& Savolainen V (2008) Iridaceae 'Out of Australasia'? Phylogeny, biogeography, and divergence time based on plastid DNA sequences. Systematic Botany, 33:495-508.

Greenboim-Wainberg Y, Maymon I, Borochov R, Alvarez J, Olszewski N, Ori N, Eshed Y \& Weissa D (2005) Cross talk between gibberellin and cytokinin: the Arabidopsis GA response inhibitor SPINDLY plays a positive role in cytokinin signaling. Plant Cell, 17:92-102.

Gupta R \& Chakrabarty SK (2013) Gibberellic acid in plant: still a mystery unresolved. Plant Signaling \& Behavior, 8:e25504.

Hepworth J \& Lenhard M (2014) Regulation of plant lateralorgan growth by modulating cell number and size. Current Opinion in Plant Biology, 17:36-42.

Jasinski S, Piazza P, Craft J, Hay A, Woolley L, Rieu I, Phillips A, Hedden P \& Tsiantis M (2005) KNOX action in Arabidopsis is mediated by coordinate regulation of cytokinin and gibberellin activities. Current Biology, 15:1560-1565.

Jevremovic S, Jeknic Z \& Subotic A (2013) Micropropagation of Iris sp. Methods in Molecular Biology, 11013:291-303.

Junqueira AH \& Peetz MS (2017) Brazilian consumption of flowers and ornamental plants: habits, practices and trends. Ornamental Horticulture, 23:178-184.

Livne S, Lor VS, Nir I, Eliaz N, Aharoni A, Olszewski NE, Eshed Y \& Weiss D (2015) Uncovering DELLA-independent gibberellin responses by characterizing new tomato procera mutants. Plant Cell, 27:1579-1594.

Lubbe CS, Siebert SJ \& Cilliers SS (2011) Floristic analysis of domestic gardens in the Tlokwe City Municipality South Africa. Bothalia, 41:351-361.

Maekawa T, Maekawa-Yoshikawa M, Takeda N, Imaizumi-Anraku H, Murooka Y \& Hayashi M (2009) Gibberellin controls the nodulation signaling pathway in Lotus japonicus. The Plant Journal, 58:183-194.

Müller D \& Leyser O (2011) Auxin, cytokinin and the control of shoot branching. Annals of Botany, 107:1203-1212.

Murashige T \& Skoog F (1962) A revised medium for rapid growth and bio assays with tobacco tissue cultures. Physiologia Plantarum, 15:473-497.

Mushtaq S, Amjad M, Ziaf K \& Afzal I (2018) Gibberellins application timing modulates growth, physiology, and quality characteristics of two onion (Allium cepa L.) cultivars. Environmental Science and Pollution Research, 25:2515525161.

O'Brien TP \& McCully ME (1981) The study of plant structure principles and selected methods. Melbourne, Termarcarphi Pty Ltda. 352p. 
Perilli S, Moubayidin L \& Sabatini S (2010) The molecular basis of cytokinin function. Current Opinion in Plant Biology, 13:2126.

Phengphachanh B, Naphrom D, Bundithya W \& Potapohn N (2012) Effects of day-length and gibberellic acid (GA3) on flowering and endogenous hormone levels in Rhynchostylis gigantea (Lindl.) Ridl. Journal of Agricultural Science, 4:217222 .

Pooley E (1998) A Field Guide To Wild Flowers Kwazulu-Natal and the Eastern Region. Scottsville, Natal Flora Publications. $630 \mathrm{p}$.

Rabobank (2015) Floriculture Map 2015. Rabobank Industry Note 475. Available at: http://www.agripress.be/ _ S T U D I O E M M A _ U P L O A D S / d o w n 1 o a d s / 1 8b_0_1_2_3_4_5_6_7_8_9_10_11_12.pdf. Accessed on: April $25^{\text {th }}, 2018$.

Rabobank (2016) World Floriculture Map 2016: Equator Countries Gathering Speed. Available at: https://research.rabobank.com/ far/en/sectors/regionalfoodagri/worldfloriculturemap2016.html. Accessed on: July 28 ${ }^{\text {th }}, 2018$.

Rahman A-u, Nasim S, Baig I, Jalil S, Orhan I, Sener B \& Choudhary MI (2003) Anti-inflammatory isoflavonoids from the rhizomes of Iris germanica. Journal of Ethnopharmacology, 86:177-180.

Rizza A, Walia A, Lanquar V, Frommer WB \& Jones AM (2017) In vivo gibberellin gradients visualized in rapidly elongating tissues. Nature Plants, 3:803-813.

Rodriguez-Falcon M, Bou J \& Prat S (2006) Seasonal control of tuberization in potato: conserved elements with the flowering response. Annual Review of Plant Biology, 57:151-180.
Ruduœ I, Cembrowska-Lech D, Jaworska A \& Kepczynski J (2019) Involvement of ethylene biosynthesis and perception during germination of dormant Avena fatua L. caryopses induced by KAR1 or GA3. Planta, 249:719-738.

SAS Institute Inc. (2003) Statistical Analysis System user's guide. Version 8.0. Cary, Satatical Analysis System Institute. 200p.

Swain SM \& Singh DP (2005) Tall tales from sly dwarves: novel functions of gibberellins in plant development. Trends in Plant Science, 10:123-129.

Su YH, Liu YB \& Zhang XS (2011) Auxin-cytokinin interaction regulates meristem development. Molecular Plant, 4:616-625.

Tirichine L, Sandal N \& Madsen LH (2007) A gain-of-function mutation in a cytokinin receptor triggers spontaneous root nodule organogenesis. Science, 315:104-107.

Tucker MR \& Laux T (2007) Connecting the paths in plant stem cell regulation. Trends in Cell Biology, 17:403-410.

Ubeda-Toma S, Federici F, Casimiro I, Beemster TSG, Bhalerao R, Swarup R, Doerner P, Haseloff J \& Bennett JM (2009) Gibberellin signaling in the endodermis controls Arabidopsis root meristem size. Current Biology, 19:1194-1199.

Urbanova T \& Leubner-Metzger G (2016) Gibberellins and seed germination. In: Hedden P \& Thomas SG (Eds.) The gibberellins. Annual Plant Reviews. Wiley, Oxford. p.253-284.

Xu L \& Huang H (2014) Genetic and epigenetic controls of plant regeneration. Current Topics in Developmental Biology, 108:01-33.

Wybouw B \& De Rybel B (2019) Cytokinin - A developing story. Trends in Plant Science, 24:177-185.

Yamaguchi S (2008) Gibberellin metabolism and its regulation. Annual Review of Plant Biology, 59:225-251. 